\title{
Gestão democrática escolar à luz das ideias de Michel de Certeau
}

\section{School democratic management according to the ideas of Michel de Certeau Gestión democrática escolar a la luz de las ideas de Michel de Certeau}

BENEDITO JOSÉ DE QUEIROZ

http://orcid.org/0000-0003-3890-1309

Universidade do Estado do Rio Grande do Norte

Faculdade de Educação

Departamento de Educação

Rio Grande do Norte, RN, Brasil

ARILENE MARIA SOARES DE MEDEIROS

http://orcid.org/0000-0002-8151-4382

Universidade do Estado do Rio Grande do Norte

Faculdade de Educação

Departamento de Educação

Rio Grande do Norte, RN, Brasil

\begin{abstract}
Resumo: Este artigo analisa como se materializa a gestão democrática no cotidiano de duas escolas públicas estaduais na cidade de Frutuoso Gomes-RN, à luz do aporte teórico de Michel de Certeau (2014). Pauta-se na abordagem qualitativa, com a utilização de observações diretas e registros no diário de pesquisa, conforme orienta Barbosa (2010). As práticas cotidianas revelam a verticalidade das relações e pouca participação nas deliberações tomadas nas escolas. Os embates nos processos de participação e decisão coletiva parecem assustar os sujeitos que praticam e articulam a gestão escolar.
\end{abstract}

Palavras-chave: Gestão democrática. Escola pública. Cotidiano.

\begin{abstract}
This article analyzes how democratic management materializes in the daily lives of two state public schools in the city of Frutuoso Gomes-RN, according to Michel de Certeau's theoretical contribution (2014). It is guided by the qualitative approach, using direct observations and records in the research diary, as oriented by Barbosa (2010). Daily practices reveal vertical relationships, small participation in school deliberations. The conflicts in the participation and decision processes seem to frighten the subjects who practice and articulate school management.
\end{abstract}

Keywords: Democratic Management. Public School. Daily Practices. 
Resumen: Este articulo analiza cómo se materializa la gestión democrática en el cotidiano de dos escuelas públicas estaduales en la ciudad de Frutuoso Gomes-RN, a la luz del aporte teórico de Michel de Certeau (2014). Es basado en el abordaje cualitativo, con utilización de observaciones directas y registros en el diario de pesquisa, de acuerdo con las orientaciones de Barbosa (2010). Las prácticas cotidianas revelan verticalidad de las relaciones, poca participación en las deliberaciones realizadas en las escuelas. Los embates en los procesos de participación y decisión colectiva parecen asustar a los sujetos que practican y articulan la gestión escolar.

Palabras clave: Gestión democrática. Escuela Pública. Cotidiano.

\section{INTRODUÇÃO}

Por vivermos atualmente uma "democracia de baixa intensidade" (SANTOS, 2007, p. 91) na sociedade brasileira, as discussões em torno da gestão democrática escolar tornam-se bastante pertinentes. Há, dessa forma, a necessidade urgente de farejar possibilidades constitutivas de novas práticas que possam dar conta de uma ressignificação moral, ética e política da dinâmica social, almejando a construção de uma sociedade com mais justiça social e menos corrupção. O cenário de miséria e de ausência - quase absoluta - dos direitos sociais (educação, segurança, saúde, assistência social etc.), que assola, em grande parte, o povo brasileiro, é a constatação de que a tardia democracia em nosso país está, na atualidade, à deriva de um processo mais amplo e global do capitalismo financeiro, conforme afirma Santos (2016).

Falar em gestão escolar democrática nos dias de hoje é trazer à tona esse fundo social amplo e contraditório, no qual táticas e estratégias são tecidas cotidianamente pelos sujeitos em suas experiências sociais, escolares e pessoais. É preciso esclarecer que estratégias e táticas são categorias centrais no pensamento de Certeau (2014). Elas apresentam diferenças entre si, mas funcionam de maneira interdependente. Estratégias consistem no estabelecimento de relações de força (dominação), cujos sujeitos envolvidos são detentores de algum poder; já táticas são ações que produzem efeitos imprevisíveis e refletem um desvio, por isso, são dinâmicas.

$\mathrm{Na}$ gestão escolar, as estratégias se configuram através do poder de que os(as) gestores(as) e/ou as equipes gestoras fazem uso no cotidiano das escolas, enquanto as táticas se traduzem de diversas formas, a depender da capacidade inventiva dos sujeitos. Considerando que, nem sempre, as estratégias e as táticas 
empreendem relações e ações que favorecem a democracia escolar, questionamos: é possível pensar em uma escola democrática se os saberesfazeres ${ }^{1}$ (ALVES, 2001; FERRAÇO, 2007) do/no cotidiano a contrariam?

Este artigo objetiva analisar a gestão democrática no cotidiano de duas escolas públicas estaduais de Frutuoso Gomes-RN, considerando o princípio da gestão democrática do ensino público, proclamado pela Constituição Federal de 1988 e ratificado pela Lei de Diretrizes e Bases (LDB - Lei n. 9.394/1996). As suas evidências decorrem dos resultados de uma pesquisa que buscou responder à seguinte pergunta de partida: Como se materializa a gestão democrática nos contextoscotidianos das escolas públicas estaduais na cidade de Frutuoso Gomes$\mathrm{RN}$ ?

$\mathrm{O}$ referido município tem 4.233 habitantes e pertence à mesorregião Oeste Potiguar, a $349 \mathrm{~km}$ de Natal (capital potiguar), no sentido Noroeste, rumo ao estado da Paraíba. É no cenário de uma cidade pequena, longe dos grandes centros urbanos e com sérios problemas sociais e infraestruturais que discutiremos a gestão democrática no cotidiano das escolas, levando em consideração as relações e as vivências dos sujeitos nos diferentes espaçostempos institucionais.

As precárias condições sociais, educacionais e econômicas de Frutuoso Gomes-RN são evidenciadas pelo Instituto Brasileiro de Geografia e Estatística (IBGE, 2010) e pelo Atlas de Desenvolvimento Humano no Brasil (ADHB, 2013), ao apontarem que o Índice de Desenvolvimento Humano (IDH) do município era de 0,597 , o que o situava na faixa de Desenvolvimento Humano Baixo (IDH entre 0,500 e 0,599). No ranking, Frutuoso Gomes passou a ocupar a $4215^{\circ}$ posição entre os 5.565 municípios brasileiros, segundo seu IDH. Esse fato o destacou como um município pobre, com profundas dificuldades sociais e políticas a serem sanadas pelo poder público.

Antes de prosseguirmos nas discussões, explicitamos que entendemos contextoscotidianos como espaçostempos de produção de saberesfazeres, que possibilitam aos sujeitos apropriação criativa em seus diferentes modos de pensar e agir, cujos significados e sentidos manifestam-se como construções socioculturais engendradas pela pluralidade e pela subjetividade dos sujeitos em suas realidades escolares. Tal entendimento consiste em uma aproximação e apropriação do aporte teórico-metodológico usado por autores cotidianistas, como: Alves (2001), Certeau (2014), Ferraço (2001, 2007), Oliveira (2001, 2005) e Barbosa (2010)², os quais buscam apreender por meio dos diferentes sentidos como os sujeitos

\footnotetext{
1 Bricolagem sugerida por Alves (2001) e Ferraço (2007). Doravante, neste artigo, o uso de outras possibilidades de bricolagem será recorrente.

2 É fundamental ressaltar que esse autor se utiliza da abordagem multirreferencial. Para um exercício de aproximação entre a multireferencialidade e Certeau, ver Ribeiro (2015).
} 
tecem o pano de fundo da democracia em vários momentos vivenciados nas escolas. A priori, entendemos como gestão democrática aquela que pressupõe possibilidades de participação dos sujeitos que constituem a comunidade escolar (pais, alunos, professores, funcionários, membros do Conselho Escolar), assim como a que considera as relações internas e externas com a comunidade local, que se constituem na horizontalidade e no reconhecimento da pluralidade, mediante as quais os sujeitos vão estabelecendo seus vínculos e suas invenções. Nesse sentido, fica o esclarecimento de que

uma sociedade [escola] democrática, não é, portanto, aquela na qual os governantes [gestores] são eleitos pelo voto. A democracia pressupõe uma possibilidade de participação do conjunto dos membros da sociedade em todos os processos decisórios que dizem respeito à sua vida cotidiana, sejam eles vinculados ao poder do Estado ou a processos interativos cotidianos, ou seja, em casa, na escola, no bairro etc. (OLIVEIRA, 2005, p. 11).

Ao refletirmos sobre a gestão democrática à luz do referencial certeauniano, de um lado, compreendemos que a democracia representativa (escolha pelo voto) não dá conta de entender a dinâmica do cotidiano, que se faz e se (re)inventa de maneira não autorizada, porque esta é caótica e imprevisível, de modo que o cotidiano não se revela em práticas previsíveis e manipuláveis. Ele é ultra autêntico. Por outro lado, não pretendemos desqualificar o processo de escolha dos gestores escolares via eleição - maneira que acreditamos ser a mais adequada -, pois entendemos que não devemos entregá-la à sorte, arriscando que haja escolhas inconsequentes pela via da arbitrariedade política. A democracia participativa é uma possibilidade existente, porque "a relação (sempre social) determina seus termos, e não o inverso, e que cada individualidade é o lugar onde atua uma pluralidade incoerente (e muitas vezes contraditória) de suas determinações relacionais" (CERTEAU, 2014, p. 38).

Todo esse contexto nos faz articular uma concepção de gestão escolar democrática que, vinculada às ideias do cotidiano, reconhece os sujeitos como "operadores" e produtores de tramas e truques, com o uso de estratégias e táticas que, segundo Certeau (2014), são duas lógicas de ações que se configuram nas relações e nas ações entre os sujeitos. As estratégias requerem espaços próprios e definidos para acontecerem; já as táticas não necessitam de espaços específicos, apropriando-se, apenas, das circunstâncias para transformar aquilo que é estranho em algo pertinente e suscitando decisões, envolvimento e participação nas diferentes ocasiões cotidianas, conforme veremos mais adiante.

Nessa lógica, a gestão escolar democrática sai de uma compreensão - até certo ponto linear, que nos leva a pensá-la apenas na esfera da representatividade (da escolha do gestor escolar ou das decisões formais nos Conselhos Escolares, 
por exemplo), como normalmente se define, para assumir a condição de espaçostempos por meio dos quais os sujeitos se fazem, (re)constituem-se e se relacionam entre si. Assim, "[...] o espaço é um lugar praticado" (CERTEAU, 2014, p. 184 , grifos do autor).

Nossa investigação trilhou os caminhos da pesquisa qualitativa, visto que a compreensão da gestão escolar democrática em seu movimento cotidiano exige uma imersão do pesquisador, no sentido de apreender as subjetividades e as pluralidades que são evidenciadas nos contextoscotidianos escolares. Para a realização deste estudo, utilizamos os seguintes procedimentos metodológicos: a revisão de literatura, tanto relacionada ao referencial certeauniano quanto à gestão escolar democrática; a análise documental, incluindo legislação nacional, estadual e documentos produzidos pela própria escola; as observações diretas de situações vivenciadas no cotidiano de duas escolas públicas estaduais no município de Frutuoso Gomes-RN, denominadas Alfa e Beta; e, por fim, as entrevistas não estruturadas com diretoras, coordenadoras pedagógicas e professoras membros dos Conselhos Escolares das escolas lócus da pesquisa.

Para efeitos deste artigo, propomo-nos a apresentar e refletir sobre dados que foram construídos a partir das observações diretas de momentos coletivos propiciados pela gestão das escolas. Esses momentos foram denominados de episódios, como forma de evidenciar que a realidade não pode ser captada em sua totalidade, mas enquanto circunstâncias diversas e adversas que compõem os contextoscotidianos dos sujeitos escolares (gestores, coordenadores, professores, funcionários e alunos). São esses fragmentos que nos possibilitam desenvolver uma compreensão acerca de como a gestão escolar democrática vem se materializando no cotidiano das escolas, evidenciando as estratégias e as táticas usadas pelos sujeitos. Priorizamos a análise de dois episódios: a) o primeiro, relacionado ao Projeto Político-Pedagógico (PPP) da Escola Estadual Beta (EEB); e b) o segundo, relativo ao Conselho Escolar (CE) da Escola Estadual Alfa (EEA), por serem considerados mecanismos fundamentais ao exercício da democracia na escola, conforme preceitua a legislação nacional.

A LDB (Lei n. 9.394/1996), em seu Artigo 12, incisos I e VI, assegura que é responsabilidade da escola elaborar e executar sua proposta pedagógica, bem como articular-se com as famílias e a comunidade, de modo a estabelecerem integração da sociedade com as instituições de ensino. Em seu Artigo 13, os incisos I e II explicitam que os docentes devem participar da elaboração da proposta pedagógica da escola e colaborar com as atividades que ensejam a articulação da escola com a sociedade e a família. No Artigo 14, os incisos I e II ratificam que a gestão escolar democrática se faz mediante a participação dos profissionais da educação na elaboração do projeto pedagógico da escola e das 
comunidades escolar e local em conselhos escolares ou equivalentes. Desse modo, seja pelas instituições de ensino, seja pelos docentes, seja pelos sistemas, a gestão democrática é uma determinação legal. Procuramos, portanto, descortinar como essa gestão vem se materializando no cotidiano das escolas a partir dos episódios que foram presenciados pelo pesquisador, enquanto realizava sua investigação.

Os episódios constituem narrativas construídas mediante as observações diretas e as anotações no diário de pesquisa, conforme nos sugere Barbosa (2010), tentando enxergar o movimento da gestão escolar numa tentativa de compreender as táticas e as criações (CERTEAU, 2014) usadas pelos praticantespensantes (OLIVEIRA, 2001) para vivenciar a gestão escolar democrática em seus contextoscotidianos escolares. As reflexões em torno da gestão democrática no cotidiano das escolas públicas estaduais de Frutuoso Gomes-RN, captando práticas e relações que realcem momentos de construção democrática, são, ao mesmo tempo, desafiadoras e encantadoras. Não é fácil captar as intenções e as (re)ações enquanto elas acontecem nos espaçostempos da gestão escolar democrática, pois os sujeitos estão “[...] envolvidos, mergulhados em movimentos de invenções e partilhas desses saberesfazeres, imbricados nas 'artes de inventar o cotidiano" (FERRAÇO, 2007, p. 83, grifo do autor).

\section{GESTÃO DEMOCRÁTICA NO COTIDIANO DAS ESCOLAS PÚBLICAS EM FRUTUOSO GOMES/RN}

No decorrer desses vinte e quatro anos em que a LDB (Lei n. 9.394/1996) se apresenta como marco legal de estruturação e funcionamento da educação brasileira, é perceptível o quanto a gestão democrática no cotidiano das/nas escolas não vem se materializando efetivamente. Os episódios observados e registrados durante a pesquisa são deflagradores de uma realidade na qual a democracia ainda permanece opaca nas escolas. É fato que em matéria de gestão democrática as instituições de ensino precisam avançar, pois existem, de um lado, escolas que continuam ignorando o que determina a Lei maior da educação brasileira, em termos de participação dos docentes e da comunidade tanto na elaboração e na execução do Projeto Político-Pedagógico quanto nas decisões pedagógicas, administrativas e financeiras via Conselho Escolar. Por outro lado, há sistemas de ensino imputando a gestão democrática, quando continuam a estabelecer o acesso ao cargo de gestor escolar por meio da indicação política e não garantem as condições para assegurar a participação dos profissionais que atuam na escola. Possivelmente, um dos grandes desafios a serem enfrentados pelo poder público consiste em envidar esforços para superar as práticas clientelistas no âmbito da 
escolha do gestor, conforme defende Medeiros (2007), e, ao mesmo tempo, para desenvolver ações que venham a corroborar com os preceitos legais do princípio da gestão democrática.

Todavia, não podemos abrir mão da defesa de uma gestão escolar democrática que favoreça a participação de docentes, pais e funcionários tanto na elaboração, discussão e acompanhamento do projeto político da escola quanto nas decisões do Conselho Escolar, conforme preceitua a LDB (Lei n. 9.394/1996), em seu Artigo 14. À luz desses dois mecanismos (Projeto PolíticoPedagógico e Conselho Escolar), a intenção é apresentar os saberesfazeres e a vivência da gestão democrática na escola pública a partir de recortes de dados empiricamente construídos por meio de observações diretas de momentos específicos, chamados de episódios, nos quais se expressam as formas/maneiras como a gestão democrática vem sendo materializada pelos praticantespensantes em suas relações, estratégias e táticas, usadas nos contextoscotidianos das escolas estaduais de Frutuoso Gomes-RN.

Consideramos por bem expor cenas que refletem a dinamicidade dos contextoscotidianos escolares, acompanhados no interior das escolas Alfa e Beta, buscando, como afirma Esteban (1999, p. 21 apud OLIVEIRA, 2005, p. 100), “[...] muitas possibilidades de interpretação dos fatos, a existência de vários percursos, desvios e atalhos [...]", para compreensão e apreensão mais detalhada das diferentes situações que ocorrem no cotidiano das escolas. Procuramos tecer fios entre o que observamos nos diferentes espaçostempos escolares e as teorias estudadas, conforme o desenrolar da maioria dos estudos que buscam compreensões sobre questões cotidianas.

Em e por princípio, todo processo democrático requer a participação dos sujeitos em todos os espaços e momentos vivenciados pelas escolas. $\mathrm{Na}$ prática cotidiana, essa não é uma tarefa fácil, pois implica a reconstrução de saberesfazeres que parecem assustar alguns sujeitos, conforme as narrativas a seguir, haja vista a necessidade de criar astúcias, burlando regras, falseando ideias e negociando alianças. As apresentações dos episódios seguem a ordem cronológica da observação. 


\section{EPISÓDIO DA ESCOLA ESTADUAL BETA (EEB) - PROJETO POLÍTICO-PEDAGÓGICO EM CENA: TÁTICAS OU ESTRATÉGIAS?}

Eram aproximadamente $14 \mathrm{~h}$ de uma terça-feira (18/08/2015), ao calor de mais de $30^{\circ}$ na Escala Celsius, quando se iniciou uma roda de conversa entre alguns sujeitos da equipe de direção e serviços administrativos da Escola Estadual Beta (EEB), envolvendo quatro profissionais. Em virtude de a cidade de Frutuoso Gomes-RN ser bastante pequena e existirem apenas duas escolas estaduais, as quais foram lócus da pesquisa, usamos pseudônimos para todos os sujeitos citados, não apontando, além disso, as funções que eles desempenham em seus espaços escolares, uma vez que estas também levariam a sua identificação.

Esse episódio começou quando Iza tomou a iniciativa e abriu a conversa com o grupo, explicitando a preocupação com a necessidade de atualização do Projeto Político-Pedagógico (PPP) da escola, expressando-se da seguinte forma: "Pensei em convocar os professores para atualizar o PPP, mas desisti; só dá uma zoada danada. Então, atualizamos, não é? E, depois apresentamos para eles [os professores] que se considerarem necessário acrescentam alguma coisa" (IZA EEB).

A partir dessa situação, percebemos que as expressões faciais de alguns sujeitos que dividiam aquele espaço apertado (diretoria/secretaria), de aproximadamente $20 \mathrm{~m} 2$, ocupado por birôs, cadeiras, armários e outros equipamentos, se modificaram. Gilka, folheando o PPP, apenas indagou ao grupo: "Então, fica acordado que atualizamos tudo e depois apresentamos, não é assim?" (GILKA - EEB).

Dando sequência à conversa, Pedro, numa espécie de enaltecimento do documento (PPP), evidenciou o quanto este estava perfeito, deixando claro que ele, a coordenadora pedagógica anterior e outros sujeitos da equipe de direção foram os construtores e reconhecendo que a redação estava impecável, embora fosse "de fachada", a missão, a visão de futuro e as concepções de escola, homem e sociedade apresentadas. Além disso, pontuou: "O que precisam ser reestruturadas são as metas e ações e nem todas, porque algumas ainda não foram atingidas ou realizadas" (PEDRO - EEB). Em meio às conversas, Jung concordou com as colocações dos demais presentes na roda de conversa e afirmou: "Isso é só para dizer que tem; mera burocracia, o importante é ter" (JUNG - EEB).

Após todas as colocações dos sujeitos do grupo, Iza demonstrou preocupação em atualizar os dados socioeconômicos dos alunos e de seus familiares. Imediatamente, solicitou a impressão do questionário aplicado em anos anteriores, que, naquela mesma tarde, foi distribuído para os alunos para que 
fosse respondido em casa com os pais e devolvido no dia seguinte. Isso causou certa agitação nos alunos, os quais perguntavam para que era aquilo, de modo que alguns indagavam: "se não trouxer tem alguma coisa?". Surpreendentemente, Lucas entrou naquele espaço apertado e, ouvindo a conversa, deixou claro desconhecer o PPP, expressando-se assim: "Ah! Aqui tem PPP? Preciso fazer uma leitura, para ver o que posso adequar ao meu trabalho" (LUCAS - EEB).

No mesmo instante, meio assustada, Iza respondeu a Lucas da seguinte forma: "Ao chegar na escola tive a intenção de deixar o PPP em cima dos birôs da diretoria/secretaria, mas fui orientada que deveria guardá-lo e se alguém o solicitasse apresentava" (IZA - EEB). Imediatamente, Iza olhou para todos ali presentes e afirmou: "Por hoje, fizemos o que podíamos, amanhã receberemos os questionários e em seguida faremos as análises dos dados socioeconômicos desses meninos" (IZA - EEB). Todos concordaram e encerraram a roda de conversa.

A partir do que foi narrado acima, podemos pontuar vários aspectos para suscitar a reflexão acerca do processo democrático no âmbito da EEB, que se apresenta pouco compreendido pelos sujeitos que estão à frente do núcleo gestor da escola (direção, vice-direção, coordenação e assistentes), tendo em vista que eles parecem assustados com os debates que a democracia possibilita nos processos de construção e decisão coletiva. $O$ intrigante é que as razões para bloquear os processos democráticos são bastante rasantes, uma vez que os debates são arrefecidos em nome de uma possível "ordem na escola", provocando o silenciamento e o distanciamento dos principais envolvidos no processo pedagógico (professores, alunos, funcionários etc.) e nas decisões que dizem respeito ao Projeto Político-Pedagógico.

Nesse contextocotidiano, a democracia assume o sentido de baderna, desordem. São essas (in)compreensões que, de um lado, dificultam a execução do princípio da gestão democrática do ensino público, porque o encaminhamento dado pela escola reflete uma estratégia de manipulação, com a nítida intenção de isolar os sujeitos de querer e poder (CERTEAU, 2014). É a equipe gestora (diretora, coordenadora, secretária etc.), demonstrando sua relação de forças quando, calculadamente, esvazia o debate e as possibilidades de construção coletiva do Projeto Político-Pedagógico. Por outro lado, para reforçar tal princípio no cotidiano da escola, a ideia de constituir uma comissão é um aspecto salutar, desde que ela fosse escolhida por e entre os pares e não uma mera imposição da equipe gestora da instituição. A imposição traduz uma tática da equipe gestora que burla as regras democráticas, quando não aceita que pessoas e profissionais com perspectivas diferentes de pensar e de enxergar a escola possam se integrar 
ao debate, considerando que "[...] as táticas apontam para uma hábil utilização do tempo, das ocasiões que apresenta e também dos jogos que introduz nas fundações de um poder" (CERTEAU, 2014, p. 96, grifo do autor).

Depois de três décadas de sanção da Constituição Federal pelo Congresso Nacional e de pouco mais de duas décadas da promulgação da LDB (Lei n. 9.394/1996) - duas referências fundamentais para orientar as escolas, os profissionais e os sistemas de ensino quanto ao princípio da gestão democrática -, a prática e a vivência desta não mais deveriam assustar a equipe gestora, pois democracia não é silenciamento, tampouco baderna. A acepção de democracia aqui defendida pressupõe possibilidades de participação dos sujeitos em todos os processos decisórios que dizem respeito à vida escolar, inclusive, com a presença de posições divergentes.

Considerando o exposto, corroboramos Maia e Costa (2013), (re) afirmando que a escola tem enormes desafios a superar para materializar a vivência da gestão democrática em seu cotidiano. Dentre eles, destacamos: a eliminação das relações competitivas e de práticas corporativas e a efetivação da participação de todos os sujeitos nos processos de planejamento e execução das ações pedagógicas, administrativas e financeiras, de modo que possam se sentir parte dos/nos processos que ocorrem no cotidiano escolar. É fundamental que a democratização da gestão escolar ocorra de modo a abrir possibilidades para reflexões que possam levar o grupo a "[...] compreender o que antes não compreendia, [de modo a começar] [...] a ver o que antes não via [...]” (OLIVEIRA, 2005, p. 101).

A narrativa mostra que a noção de democracia, com efetiva participação dos sujeitos nos processos de construção e decisões político-pedagógicas da escola, se apresenta fragilizada por uma cultura ordinária que nega a complexidade das relações sociais engendradas no cotidiano da escola, abafando inclusive as possibilidades de resistências. No entanto, precisamos compreender que qualquer tentativa no sentido de modificar o instituído é louvável, mesmo que correspondam a microações que podem ser definidas como gestão democrática. A partir do exposto, entendemos que não existe uma única maneira de enxergar os fatos e acontecimentos que ocorrem nos contextoscotidianos escolares, pois os significados e sentidos atribuídos à democracia e, por conseguinte, à gestão democrática escolar são polissêmicos e dependem do contexto e do modo como os sujeitos se apropriam das informações, das decisões, do planejamento e da execução das atividades e/ou ações vivenciadas cotidianamente nos diferentes espaçostempos e momentos escolares. 


\section{EPISÓDIO DA ESCOLA ESTADUAL ALFA (EEA) - CONSELHO ESCOLAR EM EVIDÊNCIA: ATALHOS OU VIAS JÁ PERCORRIDAS?}

Eram exatamente $15 \mathrm{~h}$ do dia 29 de outubro de 2015, uma quinta-feira, quando a sirene da Escola Estadual Alfa fez seu alarde, avisando aos alunos que estavam liberados das duas últimas aulas. Estudantes e alguns pais começaram, então a entrecruzar-se no portão de saída. Os primeiros saltitavam de alegria por terem sido liberados das aulas e os segundos, alguns sorridentes, outros bem sisudos, entravam para participar de uma reunião de pais e mestres, por convite de Clara.

Ao chegarem, foram logo ocupando as cadeiras enfileiradas no grande pátio coberto: melhor local da escola para acomodar uma quantidade superior a quarenta pessoas. Passados alguns minutos, Clara deu boas-vindas aos presentes e informou a pauta a ser discutida no encontro. Os pontos abordados foram: falta de professor de Língua Portuguesa, devido à remoção da professora que ministrou a disciplina até o $3^{\circ}$ bimestre; cronograma de avaliações para o $4^{\circ}$ bimestre; divulgação do resultado anual, das provas finais e dos exames especiais, com datas previamente definidas.

A falta de professor de Língua Portuguesa para fechar o ano letivo não agradou os presentes. Notamos alguns olhares, gestos e expressões faciais de inquietação, mas apenas uma mãe de um dos alunos do $9^{\circ}$ ano do Ensino Fundamental questionou: "E aí, como vai ficar?" (EVA - EEA).

Após esse questionamento, Dimas se levantou e começou a explicar a situação, dizendo que considerava angustiante ter que discutir a resolução do problema com os pais, mas que necessitava relatar o fato para que todos compreendessem. Esclareceu que a remoção da professora não ocorreu pelos trâmites normais, pois foi feita diretamente e de forma impensada pela Diretoria Regional de Educação e Cultura (DIREC), sem qualquer parecer da escola e sem enviar outro professor para substituí-la, causando verdadeiro transtorno à comunidade escolar. "Por isso, buscamos alternativas de solução para o problema junto a vocês [pais] e demais aqui presentes" (DIMAS - EEA).

Diante da ausência de um professor titular para ministrar a disciplina, ficou esclarecido que os alunos já tinham notas suficientes para aprovação, uma vez que todos apresentaram nota igual ou superior a 9,0 (nove) em cada um dos três primeiros bimestres. Portanto, para que os alunos não fossem prejudicados na conclusão do ano letivo, a escola propôs aos presentes repetir uma das notas, o que fez com que fossem aprovados por média. 
Nesse intuito, Clara retomou a palavra e colocou em votação a proposta que planejara, da seguinte forma: "Quem concorda em repetir uma das notas levante a mão" (CLARA - EEA). Momentaneamente, imaginei: ora, quem vai ser contra? Pelo que pude perceber, todos levantaram a mão, concordando com a tomada de decisão, obviamente. Mesmo assim, em tom destoante, ela indagou: "Quem for contra que venha até aqui justificar" (CLARA - EEA).

É óbvio que nenhum dos presentes fez qualquer sinal que fosse. Como forma de amenizar a situação, Olívia começou a esclarecer que as aulas de Língua Portuguesa do Ensino Fundamental $\left(6^{\circ}\right.$ ao $9^{\circ}$ ano) seriam ministradas pelos estagiários do curso de Letras - habilitação em Língua Portuguesa - da Universidade do Estado do Rio Grande do Norte (UERN), Campus Avançado de Patu-RN. Portanto, em termos de conteúdo, não teriam grandes perdas, embora tivesse receio de que os alunos matassem as aulas, por razão da não avaliação/ prova, por isso solicitou empenho e acompanhamento dos pais.

$\mathrm{Na}$ oportunidade, Dimas relatou que, em comum acordo com Clara, iriam angariar recursos próprios para gratificar uma pessoa da comunidade para dar as aulas de Língua Portuguesa no Ensino Médio, seguindo a mesma condição, ou seja, sem avaliação/prova, repetindo, portanto, para o $4^{\circ}$ bimestre, uma das notas. Nenhum pai ou professor manifestou opinião contrária às decisões apresentadas por Clara, Olívia e Dimas, ainda que não tenham sido esclarecidas as razões do que impedia a realização das avaliações do $4^{\circ}$ bimestre.

Naquele momento, por mais de uma vez, uma voz alertava aos presentes que assinassem a ata, a qual, juntamente com as assinaturas dos membros do Conselho Escolar, garantiria a legitimidade das decisões ali apresentadas e tomadas. A reunião foi encerrada com os agradecimentos de Clara aos presentes e com o oferecimento de suco e biscoitos a todos.

Fundamentados no que acabamos de narrar, realçamos que a escola vem se esforçando para vivenciar a gestão democrática em seu cotidiano, embora sejam perceptíveis alguns embaraços na condução dos processos decisórios, pois, apesar de fazer uso da transparência nas informações, a abordagem da problemática e as soluções predeterminadas não deram oportunidade de discussão para que a comunidade apresentasse alternativas de solução para o problema. É a escola por meio de seus profissionais da cúpula - utilizando estratégias para demonstrar sua relação de forças diante dos pais e da comunidade escolar. A narrativa é explícita em reforçar o quanto a escola tem receio do debate aberto, quando se prontifica em arrumar e arranjar situações mediante o uso de estratégias que coíbem as possíveis resistências e alternativas diferentes das pensadas pela escola. Nessa direção, a escola já vem com as soluções prontas, de modo que elas não são frutos das discussões amplas e abertas com a comunidade escolar. 
Segundo Paro (2000), na prática da gestão democrática, é oportuno que os diferentes segmentos da escola (professores, funcionários, pais, alunos e membros do Conselho Escolar) tomem consciência das dificuldades pelas quais a escola está passando, a fim de que procurem desenvolver ações para superá-las. Do contrário, a participação fica comprometida e reduzida apenas à "participação como presença" (LÜCK, 2011, p. 36), por meio da qual os sujeitos são partes do processo, mas não participam ativamente das soluções e da construção da realidade da qual fazem parte, conforme afirma Lück (2011).

Considerando esses argumentos, passamos a entender que a gestão democrática da escola pública se consolida com a abertura de espaçostempos escolares em que os diferentes sujeitos se autorizam cotidianamente no exercício de suas práticas, na busca pelo atendimento das necessidades das comunidades escolar e local, sem necessariamente vinculá-las às determinações dos poderes centrais do Ministério da Educação (MEC) ou da Secretaria de Estado da Educação e da Cultura (SEEC) do RN.

Nessa lógica, a escola passa a ser compreendida como espaço privilegiado para o fortalecimento da democracia, na medida em que nela são estabelecidas relações entre os saberes singulares e plurais que os sujeitos trazem do convívio social, que acabam influenciando e/ou sendo incorporados aos saberesfazeres escolares. Apesar de essa forma de enxergar a escola ser bastante recorrente, pensamos que somente se constitui enquanto prática se os sujeitos que dela fazem parte conseguirem definir claramente quais são suas finalidades e como prosseguilas para alcançar maior sucesso no funcionamento e no desenvolvimento de práticas diferenciadas, comprometidas com as mudanças internas da escola, estando elas vinculadas às dimensões administrativa, pedagógica e financeira.

Embora não tenha ficado claro que naquele momento o Conselho Escolar estava presente para participar de uma forma ou de outra das decisões ali apresentadas e tomadas, percebemos uma certa preocupação em documentar em ata com assinatura dos presentes e dos conselheiros, para garantir legitimidade às decisões, uma vez que a participação do referido colegiado no processo decisório atende a um dos princípios da Gestão Democrática do Ensino Público, assegurado na Constituição Federal de 1988 e na LDB (Lei n. 9.394/1996).

Com isso, fica evidente que os sujeitos articuladores do encontro entendem que o Conselho Escolar é um dos pilares da gestão democrática que, no exercício de suas funções consultivas, deliberativas e fiscalizadoras, proporciona uma rede de articulações entre escola, famílias e comunidade local, com ampla possibilidade de descentralização e autonomia dos/nos processos escolares. Embora essa compreensão faça parte do jogo que é jogado na escola, com todos os truques e tramas que o cotidiano constrói, as maneiras de condução acabam 
não reforçando tal possibilidade, porque “[...] as práticas cotidianas são igualmente definíveis como manipulações internas a um sistema - o da língua ou ao de uma ordem estabelecida" (CERTEAU, 2014, p. 85). Nesse caso, a ordem estabelecida era os alunos concluírem seu ano de estudo, sem serem prejudicados por uma determinação sistêmica, que foi a remoção da professora de Língua Portuguesa, sem nenhuma negociação ou diálogo com a escola. Em geral, a ordem de cima para baixo não constitui um simples atalho do percurso, mas uma via recorrente nos contextoscotidianos das escolas.

Não menos relevante é o reconhecimento da importância do Conselho Escolar enquanto mecanismo de democratização da gestão escolar, embora sua expressividade diante da situação apresentada na reunião confirme que o Conselho Escolar "[...] tem servido apenas para referenciar o que já vem pronto da direção. [...] serve para legitimar o que os professores, coordenadores, diretor já conversaram e decidiram" (PARO, 2007, p. 100). Esse fato demonstra a necessidade de inventar, criar outras práticas para que a gestão democrática não se configure apenas como retórica de seus praticantespensantes.

\section{CONSIDERAÇÕES FINAIS}

As análises sobre a materialização da gestão democrática nos contextoscotidianos das escolas públicas referenciadas neste artigo evidenciam, através dos episódios narrados a partir de observações diretas nos contextos escolares, compreensões enviesadas dessa prática, visto que as iniciativas de participação dos sujeitos na gestão dos processos educativos, ainda pontuais e acanhadas, são, muitas vezes, defendidas equivocadamente como gestão democrática. As estratégias e táticas usadas pelas equipes gestoras das duas escolas são, em geral, inibidoras de uma gestão democrática, por dificultarem o acesso ao debate e às decisões coletivas, reforçando verticalidade nas relações, descredibilidade e desconhecimento de seus projetos, bem como não envolvimento de todos os segmentos nos processos de elaboração e decisão coletiva. Os profissionais da cúpula gestora preferem se utilizar da tática de chegar com as soluções prontas, porque confundem democracia com baderna e com mera socialização de informações.

À luz das narrativas, a democratização da gestão se encontra bastante incipiente, visto que as estratégias e táticas foram pouco ousadas no que concerne à participação e ao envolvimento dos sujeitos. No primeiro episódio, o processo democrático foi frustrado sob a justificativa de que um maior envolvimento dos sujeitos na atualização do Projeto Político- Pedagógico levaria à desordem, à baderna, impossibilitando a discussão, a pluralidade de ideias e pensamentos 
divergentes. No segundo episódio, o processo democrático também é pouco evidente, uma vez que os sujeitos participam apenas legitimando decisões tomadas previamente pela equipe gestora, sem debates e apresentação de outras sugestões e encaminhamentos dos demais segmentos da comunidade escolar para as demandas apresentadas.

O processo de gestão democrática é bastante contraditório e descontínuo. É plasmado por estratégias e táticas inusitadas, porque os sujeitos entram num jogo ambivalente: "Faz o contrário daquilo que diz" (CERTEAU, 2014, p. 197). Pelo menos é dessa forma que eles se apresentam nos contextoscotidianos das duas escolas pesquisadas, sendo que em uma ocorre de maneira mais acentuada do que na outra. Mesmo assim, os contextoscotidianos são muito dinâmicos e possibilitam aos praticantespensantes diferentes sentidos e significados à democracia, por isso nossas análises, às vezes, se relativizam e os resultados não se apresentam como fechados, ou seja, como verdades únicas, mas apenas como meios de aproximar a leitura do vivenciado e do praticado nos contextoscotidianos das escolas lócus da pesquisa. Aproximar as discussões da gestão democrática com o referencial de Certeau (2014) é se deparar com a necessidade de fuga dos padrões convencionais e com a linearidade que apresenta a maioria das produções científicas. É se abrir para o (in)certo, para as oscilações em sua exploração. Com esse entendimento, tentamos "[...] produzir/inventar 'novas' e 'momentâneas' alternativas de análises [...]” (FERRAÇO, 2001, p. 92) que nos permitem diferentes compreensões e apreensões sobre a materialização da gestão democrática nos referidos contextoscotidianos escolares.

Diante dos dados construídos, a gestão democrática ainda não está consolidada, uma vez que nossas análises encontram vários aspectos que indicam resistências à abertura de canais que favoreçam a participação de todos os sujeitos nos diferentes espaçostempos que necessitam ser compartilhados, de modo que as relações sejam mais favoráveis à vivência da democracia nos cotidianos escolares. Nessa lógica, a gestão democrática da escola pública se constitui mais no campo teórico do que no prático, pois as discussões e embates, que possivelmente ocorrerão nos processos de participação e decisão coletiva, parecem assustar parte dos praticantespensantes em seus contextos escolares. No entanto, entendemos que tais obstáculos, se tomados como parte de um processo que é contraditório, imprevisível, podem, em outras circunstâncias, favorecer novas estratégias e táticas dos sujeitos em seus espaçostempos escolares, que contribuam para a materialização da gestão democrática. 


\section{REFERÊNCIAS}

ALVES, Nilda. Decifrando o pergaminho: o cotidiano das escolas nas lógicas das redes cotidianas. In: OLIVEIRA, Inês Barbosa; ALVES, Nilda (org.). Pesquisa no/do cotidiano das escolas: sobre redes de saberes. Rio de Janeiro: DP\& A, 2001. p. 13-38.

ATLAS DO DESENVOLVIMENTO HUMANO NO BRASIL. Disponível em: http://www.atlasbrasil.org.br/2013/pt/perfil_m/frutuoso-gomes_rn. Acesso em: 16 maio 2015.

BARBOSA, Joaquim Gonçalves; HESS, Remi. O diário de Pesquisa: o estudante universitário e seu processo formativo. Brasília: Liberlivro, 2010.

BASTOS, João Baptista. Gestão democrática da educação: as práticas administrativas compartilhadas. In: BASTOS, João Baptista (org.). Gestão democrática. 2. ed. Rio de Janeiro: DP\&A/SEPE, 2001. p. 7-30.

BASTOS, João Baptista. Gestão democrática e pensamento liminar. In: FREIRE, Wendel. Gestão democrática: reflexões e práticas do/no cotidiano escolar. Rio de Janeiro: Wak, 2009. p. 143-162.

BRASIL. [Constituição (1988)]. Constituição da República Federativa do Brasil. Brasília, DF: Senado Federal, Subsecretaria de Edições Técnicas, 2004.

BRASIL. Lei n. 9.394 de 20 de dezembro de 1996. Estabelece as Diretrizes e Bases da Educação Nacional. LDB: Diretrizes e Bases da Educação Nacional. 2. ed. Brasília, DF: Câmara dos Deputados, Coordenação de Publicações, 2001.

CERTEAU, Michel. A invenção do cotidiano: artes de fazer. Tradução de Ephaim Ferreira Alves. 22. ed. Petrópolis: Vozes, 2014.

FERRAÇO, Carlos Eduardo. Ensaio de uma metodologia efêmera, ou sobre as várias maneiras de sentir e inventar o cotidiano escolar. In: OLIVEIRA, Inês Barbosa; ALVES, Nilda (org.). Pesquisa no/do cotidiano das escolas: sobre redes de saberes. Rio de Janeiro: DP\&A, 2001. p. 91-107.

FERRAÇO, Carlos Eduardo. Pesquisa com o cotidiano. Educação e Sociedade, São Paulo, v. 28, n. 98, p. 73-95, jan./abr. 2007. 
INSTITUTO BRASILEIRO DE GEOGRAFIA E ESTATÍSTICA. Censo 2010: Atlas Digital Brasil. Disponível em: http://www.ibge.gov.br/home/. Acesso em: 16 maio 2015.

LÜCK, Heloisa. A gestão participativa na escola. Petrópolis: Vozes, 2011. v. III.

MAIA, Benjamin Perez; COSTA, Margarete Terezinha. Os desafios e as superações na construção coletiva do projeto político-pedagógico. Curitiba: InterSaberes, 2013.

MEDEIROS, Arilene Maria Soares. Administração educacional e racionalidade: o desafio pedagógico. Ijuí: Unijuí, 2007.

OLIVEIRA, Inês Barbosa. Certeau e as artes de fazer: as noções de uso, tática e trajetórias na pesquisa em educação. In: OLIVEIRA, Inês Barbosa; ALVES, Nilda (org.). Pesquisa no/do cotidiano das escolas: sobre redes de saberes. Rio de Janeiro: DP\&A, 2001. p. 39-54.

OLIVEIRA, Inês Barbosa (org.). A democracia no cotidiano da escola. 3. ed. Rio de Janeiro: DP\&A/SEPE, 2005.

PARO, Vitor Henrique. Gestão democrática da escola pública. 3. ed. São Paulo: Ática, 2000.

PARO, Vitor Henrique. Gestão escolar, democracia e qualidade do ensino. São Paulo: Ática, 2007.

RIBEIRO, Mayra Rodrigues Fernandes. A sala de aula no contexto da cibercultura: formação docente e discente em atos de currículo. Tese (Doutorado em Educação) - Universidade do Estado do Rio de Janeiro, Rio de Janeiro, 2015

SANTOS, Boaventura de Sousa. Renovar a teoria crítica e reinventar a emancipação social. Tradução de Mouzar Benedito. São Paulo: Boitempo, 2007. 


\section{Benedito José de Queiroz}

Mestre em Educação pela Universidade do Estado do Rio Grande do Norte (UERN), Pós Graduado em Gestão escolar (UFRN), Graduado em Pedagogia (UFPB). Professor Efetivo no Ensino Médio da Escola Estadual Ivonete Carlos, da Rede Estadual de Ensino do Rio Grande do Norte. Atuou como Gestor Escolar da referida escola, no período de 2008 a 2011. E-mail: bjqueiroz16@ gmail.com

\section{Arilene Maria Soares de Medeiros}

Doutora em Educação pela Universidade Federal de São Carlos (UFSCar), professora e pesquisadora da Faculdade de Educação, da Universidade do Estado do Rio Grande do Norte, atuando no ensino da graduação (Curso de Pedagogia) e da pós-graduação stricto sensu (Mestrado em Educação). Coordenou o Programa de Pós-Graduação em Educação no período de 2011 a 2014. E-mail: arilenemaria.medeiros@gmaill.com 